\title{
AN ALTERNATIVE FOR FLOOD CONTROL IN THE ICARAÍ RIVER BASIN, NITERÓI CITY, RIO DE JANEIRO, BRAZIL
}

\author{
Ivan Aurélio Fortuna Kalil de Faria ${ }^{I}$ \\ Gustavo Carneiro de Noronha ${ }^{2}$ \\ Mônica de Aquino Galeano Massera da $\mathrm{Hora}^{3}$
}

\begin{abstract}
This paper demonstrates that it is possible to implement a flood control system (called "piscinão") in Niterói city, located in Rio de Janeiro State, Brazil composed by a reservoir that retains temporally the storm water. The recommended design storm equation and flood routing were applied in order to design the reservoir capacity. The results indicate that it is feasible to implement such solution, reducing more than two thirds of the peak discharge downstream, thus mitigating the damages caused by flood in Niterói city.
\end{abstract}

Keywords: flood control, reservoir, flood routing.

\footnotetext{
${ }^{1}$ Professional Master Program in Defense and Civil Security. E-mail: ivankalil@yahoo.com.br

${ }^{2}$ LabHidro - Water Resources and Environment Laboratory, Federal Fluminense University. E-mail: gcnoronha@vm.uff.br

3 LabHidro - Water Resources and Environment Laboratory, Federal Fluminense University. E-mail: dahora@vm.uff.br
} 


\section{INTRODUCTION}

According to Niemczynowicz (1999), water-related infrastructure in urban areas is very expensive, and requires constant economical input to maintain its functionality. Many technologies have been developed to minimize the impacts of floods. Currently, a technology that is proving promising to minimize flood in urban areas is the retention of surplus volumes of rainfall through hydraulic structures composed of reservoirs, control and depletion structures, the so-called "piscinões".

Over the past few decades, increased urbanization has substantially reduced the size of pervious surfaces in urban areas. New impervious surfaces such as roadways and roofs, together with developed commercial areas, have effectively increased the peak storm discharge to such an extent that frequent failure of the existing drainage systems is not uncommon (Chan and Bras, 1979).

The current model of urbanization of the Brazilian cities has proved inadequate and disorganized, particularly in relation to the drainage system. Due to the growth of the city, the designed drainage system is now undersized, causing problems in various proportions, such as overflow, traffic disorder, flood, landslide, etc. In many cases, this drainage system is not resized because of high project and execution cost, since the cities grow at a much higher speed than the budget needed for this type of intervention.

To minimize the impacts of overflow and flooding, cities have targeted alternative solutions, such as the construction of reservoirs, dams, diversion of water courses, among others. In addition to these physical interventions, some of them have introduced public policies to complement urban flood control. The cities of Rio de Janeiro, Guarulhos, São Carlos, Porto Alegre, Ribeirão Preto, Osasco and São Paulo have adopted similar ideas in this direction. These cities use rainwater reservoirs with subdivisions that have some percentage of impervious area, this percentage varying according to the criteria adopted by each city for the temporary holding of the stormwater that precipitates on each lot. Thus, these lots contribute to delay the runoff of waters to the public drainage system, slowing the flow of rainwater, controlling, damping and minimizing problems arising from flow peak, facilitating the operation of the system.

The mayor of Niterói city enacted Law 2630 on January 7, 2009, which states that new buildings, public or private, shall be provided with a rainwater reservoir, with accumulated or delayed system. For the construction of the reservoir, the law provides the following conditions: resistance to mechanical stress, easy access for maintenance, existence of spillways and discharge orifice sized up so as to limit the maximum flow of the orifice at $20 \%$ of the superficial outflow of the sealed area, considering the maximum intensity of the precipitation corresponding to a return period of 10 years.

\section{TEMPORARY ACCUMULATION RESERVOIRS}

Stormwater source control has become a popular alternative solution for managing stormwater in urban areas (Martin et al., 2006). An urban solution to minimize the contribution of rainwater in urban drainage system is the reservoirs for temporary accumulation. According to Netto (2004), there are two types of accumulation, regardless the dimensions of the reservoir, uncontrolled and controlled, see Figures 1 and 2. In the uncontrolled accumulation, there is no regulation of outflow capacity, the structures usually have reduction systems for the outflow and their only advantages, in the floods, result from the effects of the modification and delay of storage. In controlled accumulation, the floodgates of the structures can regulate the runoff. 


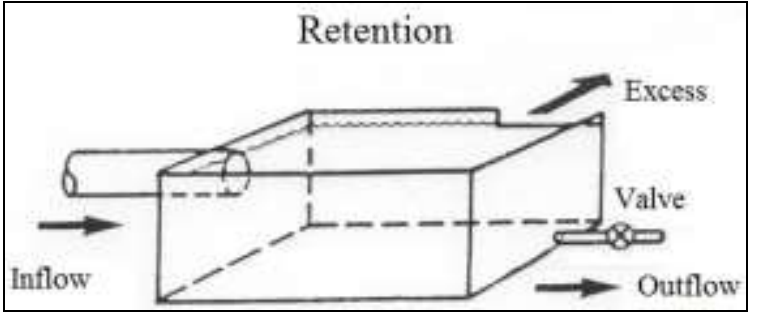

Figure 1: Reservoir with control.

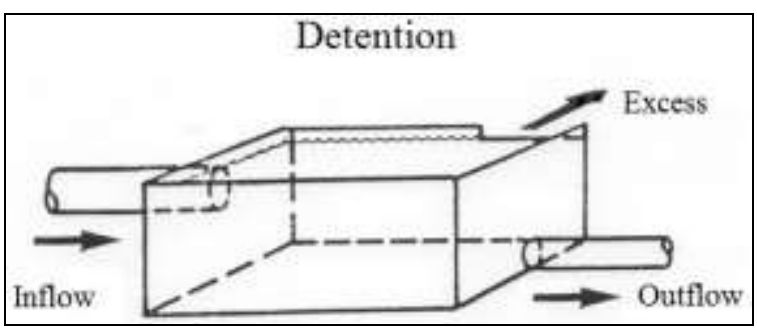

Figure 2: Reservoir without control.

The triangular unit hydrograph method developed by the Natural Resources Conservation Service (NRCS) was adopted to define the project floods and respective hydrographs. The rainfall intensity in Niterói city was calculated by the equation recommended by DER-RJ (1989) and expressed by:

$$
I=\frac{706 \cdot T^{0,333}}{(t+10)^{0,704}}
$$

where

$I$ is rainfall intensity, $(\mathrm{mm} / \mathrm{h})$.

$T$ is return period, (years).

$t$ is rainfall duration, (minutes).

The methodology of propagation and flood routing with any return period in a reservoir, considering the presence or absence of bottom outlet follows the mathematical formulation, from the continuity equation (Fenton, 1992), expressed by:

$$
\frac{d S}{d t}=I-Q
$$

where

$S$ accumulated or stored volume, in $\mathrm{m}^{3}$.

$I$ inflow, in $\mathrm{m}^{3} / \mathrm{s}$.

$Q$ outflow, in $\mathrm{m}^{3} / \mathrm{s}$.

The equation 2 can be described at discrete intervals, as follows:
$\frac{S_{t+\Delta t}+S_{t}}{\Delta t}=\bar{I}-\bar{Q}$

where $\bar{I}$ and $\bar{Q}$ represent the median values of the inflow and outflow of the reservoir along the time interval $\Delta t$.

Considering a linear variation of $I$ and $Q$ along $\Delta t$, equation 3 can be rewritten as follows:

$\frac{S_{t+\Delta t}-S_{t}}{\Delta t}=\frac{I_{t}+I_{t+\Delta t}}{2}-\frac{Q_{t}+Q_{t+\Delta t}}{2}$

where $I_{t} ; I_{t+\Delta t} ; Q_{t}$ and $Q_{t+\Delta t}$ are the values at the beginning and at the end of the time interval.

In this equation, at each time interval, the inflow at time $t$ and at $t+\Delta t$; the outflow at time interval $t$, and the stored volume at the interval $t$ are known Terms $S_{t+\Delta t}$ and $Q_{t+\Delta t}$, are not known and both depend on the water level.

The Goodrich method, cited in Schulz (1989), allows estimating the reservoir flood routing. In this method, the equation 4 is rewritten as:

$$
\frac{2 \cdot S_{t+\Delta t}}{\Delta t}+Q_{t+\Delta t}=I_{t}+I_{t+\Delta t}+\left[\frac{2 \cdot S_{t}}{\Delta t}-Q_{t}\right]
$$

where the unknown terms appear on the left side and the known terms appear on the right side.

The spillway structure was defined as being an uncontrolled spillway with standard Creager type profile, whose discharge is expressed by:

$Q_{V E R T}=C \cdot L \cdot H d^{3 / 2}$

where

$Q_{V E R T}$ spilled flow, $\left(\mathrm{m}^{3} / \mathrm{s}\right)$.

$C$ coefficient, $\left(\mathrm{m}^{1 / 2} / \mathrm{s}\right)$, and equal to 2.08 .

$L$ width of the weir crest, $(\mathrm{m})$.

$H d$ head over the weir crest, (m).

For the bottom outlet, a circular orifice was adopted. The orifice discharge can be determined using: 
$Q_{D E S C}=\mu \cdot A \cdot \sqrt{2 \cdot g \cdot H}$

where

$Q_{D E S C}$ released discharge, $\left(\mathrm{m}^{3} / \mathrm{s}\right)$.

$\mu$ is coefficient and equal to 0.6 .

$A$ orifice area, $\left(\mathrm{m}^{2}\right)$.

$g$ acceleration of gravity, equal to $9.81 \mathrm{~m} / \mathrm{s}^{2}$.

$H$ is total head, (m).

\section{RESULTS AND DISCUSSION}

The first stage of calculations consisted on the generation of flood hydrographs for maximum rainfalls and associated return periods corresponding to 3,5 and 10 years. The hydrographs were generated considering a contributing basin that covers the drainage of Noronha Torrezão and Martins Torres Channels up to the vicinity of Caio Martins Stadium. The results indicate that it would require an area the size of a stadium 120 meters wide and 250 meters long, totaling $30.000 \mathrm{~m}^{2}$ as shown in Figure 3. Thus, an alternative proposal was conceived taking into consideration the following arrangement:

- Flood routing for return period of 3, 5 and 10 years.

- Reservoir with 120 meters wide, 250 meters long and 4 meters deep, totaling $120,000 \mathrm{~m}^{3}$. The depth was chosen targeting the highest possible stored volume without creating constructive difficulties and interference with the foundations of the constructions around the stadium. The reservoir bottom elevation was set equal to zero.

- 2 meters wide spillway, 3 meters above the reservoir bottom (based on water level, volume of the reservoir and the hydrographs).

- Two outlet orifices with a diameter of 0.50 meters, each. The choice of the diameter took into account the need to restrict the outlet flow of the reservoir, so that the inflow of a great magnitude flood would generate a temporary accumulation of water in the reservoir.

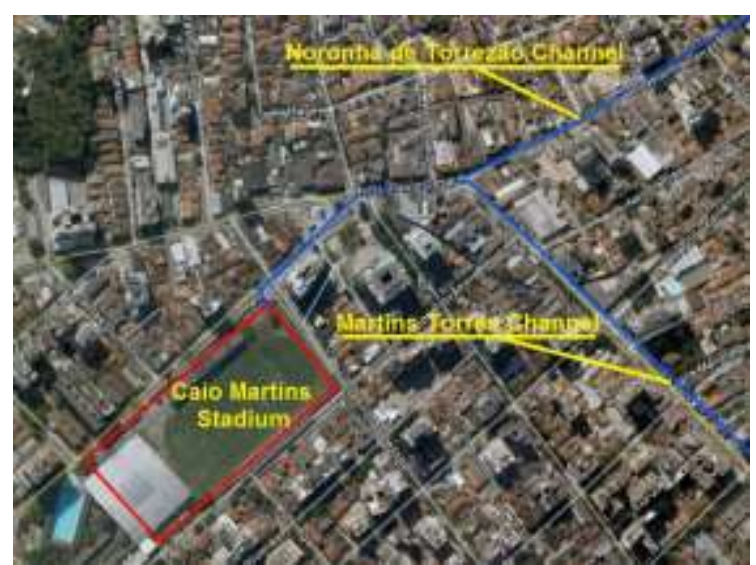

Figure 3: Area considered for the reservoir

From the proposed reservoir, the routing calculations were prepared for the recurrence times established. Figures 4 to 6 show the results achieved.

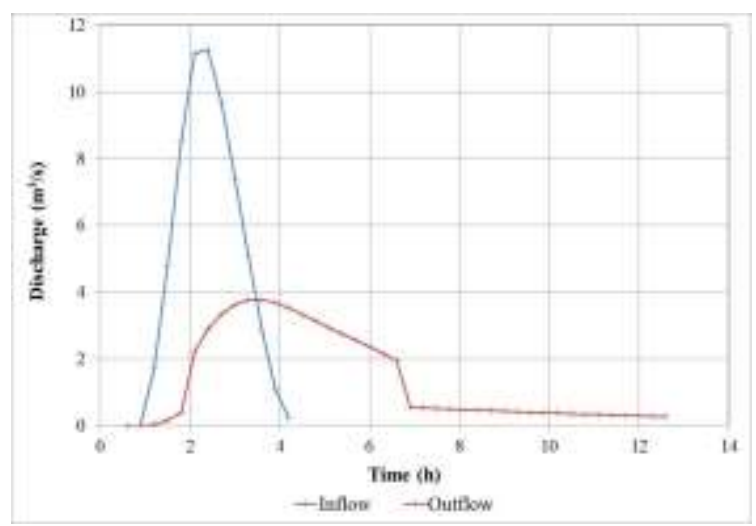

Figure 4: Inflow and released hydrographs for $\mathrm{T}=3$ years

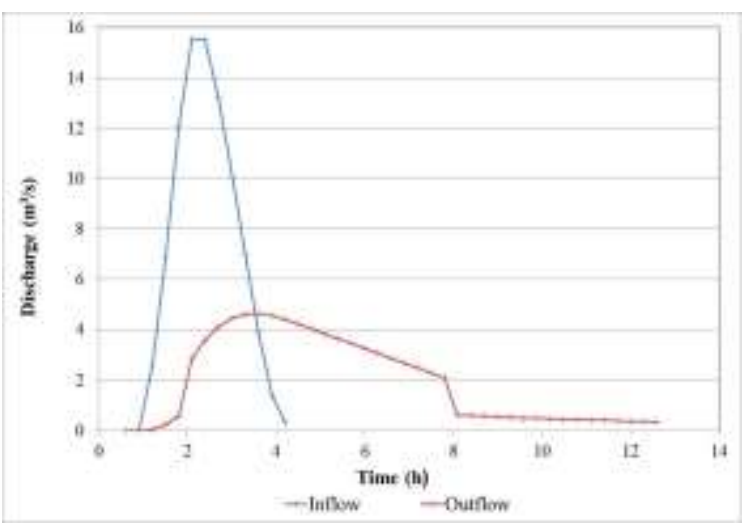

Figure 5: Inflow and released hydrographs for $\mathrm{T}=5$ years 


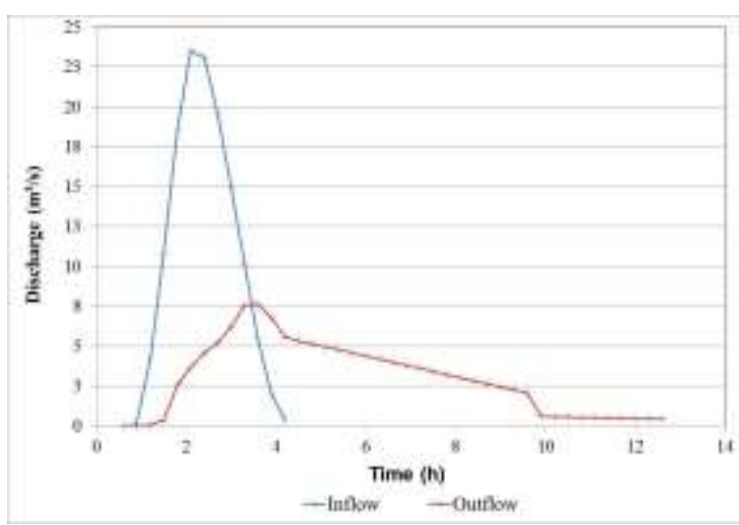

Figure 6: Inflow and released hydrographs for $\mathrm{T}=10$ years

The reservoirs constructed in cities with the purpose to absorb the flood peaks, also called "piscinoes", remain most of the time dry (waiting volume) and, during a rainfall event the water is stored and released in a controlled or uncontrolled manner. These reservoirs do not significantly reduce the volume of superficial runoff, but act on the peak outflow, reducing and extending the periods of recession of flood hydrographs (Chow et $a l .$, 1988). Their efficiency can be assessed from the relation between the released outflow and the inflow, expressed by:

$$
E=\frac{\left(Q_{\text {max inf }}-Q_{\text {max rel }}\right)}{Q_{\text {max inf }}} \cdot 100
$$

where

$E$ efficiency, (\%).

$Q_{\text {maxinf }}$ inflow peak, $\left(\mathrm{m}^{3} / \mathrm{s}\right)$.

$Q_{\text {maxrel }}$ release peak, $\left(\mathrm{m}^{3} / \mathrm{s}\right)$.

Table 1 shows the calculated values of efficiency, as well as a summary of the main results achieved in the performed simulations.

Table 1: Main results and efficiency of the reservoir flood routing

\begin{tabular}{|c|c|c|c|c|c|}
\hline $\mathbf{T}$ & $\begin{array}{c}\text { Qinf } \\
\left(\mathbf{m}^{\mathbf{3}} / \mathbf{s}\right)\end{array}$ & $\begin{array}{c}\text { Qrel } \\
\left(\mathbf{m}^{\mathbf{3}} / \mathbf{s}\right)\end{array}$ & $\begin{array}{c}\text { Water } \\
\text { Level } \\
(\mathbf{m})\end{array}$ & $\begin{array}{c}\text { Lag } \\
\text { between } \\
\text { peaks } \\
(\mathbf{m i n})\end{array}$ & $\begin{array}{c}\mathbf{E} \\
(\mathbf{\%})\end{array}$ \\
\hline 3 & 11.25 & 3.77 & 1.61 & 72 & 66.50 \\
5 & 15.55 & 4.65 & 2.31 & 90 & 70.10 \\
10 & 23.50 & 7.62 & 3.50 & 90 & 67.59 \\
\hline
\end{tabular}

The analysis of the results shows that the efficiency of the proposed reservoir is greater for a recurrence of 5 years than for a recurrence of 3 or 10 years. It is also possible to observe the behavior of the water level inside the reservoir. The setting of the depth of the reservoir at 4 meters allowed lamination of the 10 years flood with a free-board of 0.50 meters. Furthermore, it is apparent that the peaks of the inflow and outflow discharges are phased off by 72 minutes for the hydrograph of 3 years recurrence and 90 minutes for the hydrographs of 5 and 10 years recurrence.

The proposed reservoir was designed to operate in parallel (off-line) to the drainage system, i.e., the flow would be diverted from the main line to the temporary storage in a reservoir inside the Caio Martins Stadium. The efficiency was about $70 \%$ for the floods with recurrence of 5 years; $67.6 \%$ for 10 years and $66.5 \%$ for 3 years. The obtained results indicate that this solution can be very helpful in containing and mitigating the harmful effects of urban flooding in Niterói city.

Urban flood control reservoirs are increasingly used as instruments to mitigate impacts caused by urbanization of watersheds. Determining the reservoir capacity is the hardest part. However, the proposed design has shown that in many cases, the project ends up adapting itself to the available space, particularly in urban regions where the availability of areas to implement flood control reservoirs is a very restrictive condition. The authors finally suggest that the efficiency of the reservoir be improved by controlling the outflow through the orifices installing valves or gates, allowing to increase the water level inside the reservoir in order to obtain higher efficiency in hydrologic events of shorter return time.

\section{REFERENCES}

CHAN, S.O., AND BRAS, R.L. (1979) Urban storm water management: Distribution of flood volumes, Water Resour. Res., 15(2), 371-382, doi:10.1029/WR015i002p00371 
CHOW, T.V.; MAIDMENT, R.D.; MAYS, W.L. (1988) Applied Hydrology. McGrawHill Book Co., Singapore, 572 p.

DER-RJ (1989) Estudo de Chuvas do Estado do Rio de Janeiro. Departamento de Estradas e Rodagem - RJ. Relatório. Rio de Janeiro.

FENTON, J.D. (1992) Reservoir routing, Hydrological Sciences Journal, 37:3, 237243. doi: $\underline{1080 / 02626669209492584}$

MARTIN, C; RUPERD, Y.; LEGRET, M. (2006) Urban stormwater drainage management: The development of a multicriteria decision aid approach for best management practices, European Journal of Operational Research, Volume 181, Issue 1,338-349. doi:1016/j.ejor.2006.06.019

NETTO, O.M.C. (2004) Técnicas de Minimização da Drenagem de Águas Pluviais. In: Gerenciamento do Saneamento em Comunidades Organizadas, São Paulo, 4 e 5 de maio de 2004. Available on: <http://www.etg.ufmg.br/tim2/auladrenage m.ppt>. (Accessed: March, 2012).

NIEMCZYNOWICZ, J. (1999) Urban hydrology and water management - present and future challenges, Urban Water, Volume 1, Issue 1, 1-14. doi:10.1016/S1462-0758(99)00009-6

SCHULZ, E.F. (1989) Problems in Applied Hydrology. Water Resources Publications. Colorado, USA. 501p. 